\title{
Narrativa
}

\section{Serena TODESCO, Tracce a margine. Scrittura femminile nella narrativa storica siciliana contemporanea}

\section{Francesca Calamita}

\section{OpenEdition}

\section{Journals}

\section{Edizione digitale}

URL: https://journals.openedition.org/narrativa/577

DOI: $10.4000 /$ narrativa. 577

ISSN: 2804-1224

\section{Editore}

Presses universitaires de Paris Nanterre

\section{Edizione cartacea}

Data di pubblicazione: 1 décembre 2018

Paginazione: 185-186

ISBN: 978-2-84016-325-1

ISSN: $1166-3243$

\section{Notizia bibliografica digitale}

Francesca Calamita, «Serena TODEsco, Tracce a margine. Scrittura femminile nella narrativa storica siciliana contemporanea», Narrativa [Online], 40 | 2018, online dal 01 novembre 2021, consultato il 08 décembre 2021. URL: http://journals.openedition.org/narrativa/577 ; DOI: https://doi.org/10.4000/ narrativa. 577

Questo documento è stato generato automaticamente il 8 décembre 2021.

Narrativa est mise à disposition selon les termes de la Licence Creative Commons Attribution 4.0 International. 


\title{
Serena TODESCO, Tracce a margine. Scrittura femminile nella narrativa storica siciliana contemporanea
}

\author{
Francesca Calamita
}

\section{NOTIZIA}

Serena TODESCO, Tracce a margine. Scrittura femminile nella narrativa storica siciliana contemporanea, Gioiosa Marea, Pungitopo, 2016, 723 p.

1 In Tracce a margine, Serena Todesco ci invita a viaggiare da un posto all'altro della Sicilia (e del Mezzogiorno), portando alla luce il lavoro di scrittrici ben note o meno conosciute alla critica letteraria contemporanea e agli appassionati di scrittura femminile. Un volume non solo rigoroso nell'approccio investigativo ma necessario per dare voce a un gruppo di autrici escluse - ingiustamente - dal canone tradizionale. Maria Attanasio, Silvana La Spina, Maria Rosa Cutrufelli, Silvana Grasso e Giovanna Giordano affrontano nei loro romanzi storici dagli anni ' 90 all'inizio del nuovo secolo temi socio-culturali, che Todesco esplora inquadrando la sua ricerca negli studi di genere e negli studi culturali.

2 Le autrici scelte da Todesco portano sulla scena delle protagoniste che non sono intrappolate nell'atavico dualismo dell'“angelo del focolare" o della femme fatale, come spesso presentate nella letteratura canonica siciliana di Verga, Capuana, Sciascia, Consolo e Camilleri, ma personagge "scardinat[e] rispetto a metodi sociali precostituiti" (p. 21). Si tratta di donne che rifiutano il ruolo sociale di mater salvifiche o "fimminine" (pp. 175-179) e si ribellano al potere, al patriarcato e all'ordine precostituito che avrebbe voluto silenziarle. Rimangono così a margine rispetto alla società del tempo, ma è costruendosi un'identità alternativa a quella preparata per loro che riescono ad affermarsi. Attraverso il genere del romanzo storico, le scrittrici analizzate da Todesco riscrivono, dunque, le loro vicende, in cui l'interpretazione femminile non è 
complementare a quella canonica ma essenziale. In questo modo ottengono "la legittimazione di una soggettività pensante" (p. 676) e si riappropriano di una visione dei fatti libera dal pensiero maschile, decostruendo così "gli apparati simbolici dominanti" (p. 698).

3 Nella sezione "Strumenti", Todesco si sofferma anche sull'interpretazione del Mezzogiorno come luogo "femminile", soggiogato da un Settentrione "maschile" che lo percepisce come irrazionale e passionale, in preda alla superstizione e alla corruzione. Un'idea che si fortifica nella produzione letteraria verghiana, e di altri autori isolani, in cui esiste una costellazione di "donn[e] da salvare" (p. 168) che ricorda la controversa subordinazione nazionale tra il nord e il sud. Una descrizione del sud non condivisa da Attanasio, La Spina, Cutrufelli, Grasso e Giordano e manifestata attraverso la scelta di personagge socialmente libere e autonome dal pensiero maschile, in grado di contribuire all'affermazione identitaria della Sicilia e del Meridione. In questo senso, il lavoro dell'autrice si inserisce anche nel discorso sulla scrittura femminile come strumento essenziale per comprendere il dibattito ideologico sulle differenze socio-culturali della Penisola e sul concetto di nazione.

4 Il lavoro di Todesco non costituisce un punto d'arrivo, ma di partenza per lo studio della scrittura a firma femminile siciliana e ben oltre; è sintomatico della necessità di (ri)scoprire autrici della letteratura italiana che per troppo tempo sono state studiate solo in contesti a margine. Se è pur vero che negli ultimi decenni si è stabilito un canone anche nella scrittura femminile, si pensi a Aleramo, Maraini o Banti, sia nel contesto universitario sia in quello scolastico, le autrici italiane non hanno la medesima visibilità degli autori. Lo studio di Todesco contribuisce ad accorciare questa disparità, collocandosi tra quei volumi sulla scrittura femminile necessari sia nell'accademia italiana sia in quella all'estero per diminuire il gender gap letterario. 